demonstrator. My own work there consisted, at Maxwell's suggestion, in comparing the existing B.A. standards of resistance with the object of ascertaining the most probable value of the B.A. unit, the absolute value of which was afterwards determined by the work of Lord Rayleigh and Sir Arthur Schuster. For this purpose a special form of resistance balance was designed which was in use for many years afterwards at the Cavendish Laboratory.

After the lamented decease of Prof. Clerk Maxwell in 1879, Lord Rayleigh consented to hold the chair for a time in response to a universal request, and made in a few years most notable contributions to exact electrical measurement.

Then on Lord Rayleigh's retirement, Sir J. J. Thomson, now Master of Trinity College, was appointed, and began his epoch-making researches on the constitution of the atom. Under him a large number of research workers were gathered whose discoveries made the Cavendish Laboratory world-famous.

On Thomson's retirement, Lord Rutherford succeeded to the chair, and his great discoveries in radioactive matter and the structure of the atom have opened new chapters in the history of science.
With him have been associated other workers whose researches have given them fame. The work of Dr. Aston on isotopes and the discovery of the neutron by Prof. James Chadwick, and more recent work by others, such as Drs. J. D. Cockcroft and E. T. S. Walton, have made departures of an importance not easily overstated.

This donation of Sir Herbert Austin will, I believe, be devoted to the erection and equipment of a new high-voltage laboratory, where electromotive forces of a million or more volts will be employed to hurl the hardest particles in nature, namely the alpha particle, at other atoms, and so break up their nuclei. It is possible by some such process that an artificial radium may be produced with all the valuable properties of the natural radium in therapeutic work. It is impossible yet to foresee all the supreme importance of the outcome of such a new laboratory. We know already that enormous stores of atomic energy are awaiting discovery and utilisation, and this great benefaction of Sir Herbert Austin when utilised by the resourceful and able research workers in physics at Cambridge will unquestionably bring in due course not only greater knowledge but also greater benefits to mankind.

\title{
Blackpool Meeting of the British Association
}

$\mathrm{T}$ HE visits of the British Association to Lancashire have not been infrequent-they began with the Liverpool visit of 1837-and its members know, and appreciate, the traditions of Lancashire hospitality. In its history of a hundred and five years the Association has visited Liverpool six times, Manchester thrice and Southport twice. Now the Association will enlarge its experiences, having accepted for this year (September 9-16) the invitation extended by the Mayor and Corporation of the Borough of Blackpool.

Each of the great cities of the North has its special characteristics, but their civic and industrial activities may be matched in other regions. Blackpool may fairly be said to be unique. It has devoted itself to the problems of the systematisation of mass-amusements with a spaciousness which is all its own. In these, and in its municipal activities, it has preserved a pioneering energy and ability to take the long view given to it by the farsightedness of its first Mayor, the late Dr. W. H. Cocker-an ability which has made Blackpool's remarkable experiments in town lighting and traction models for other communities for more than fifty years past. The Blackpool meeting also affords special opportunities for the study of what is, in its integrity, a little-known corner of the kingdom. The Fylde is a division of England the natural features of which will well repay investigation, a division which still has its own peculiarities of thought and diction and the villages of which preserve something of the atmosphere of those days when the Industrial Revolution was not.

Sir Josiah Stamp will deliver his presidential address in the Empress Hall of the Winter Gardens. The exact title of the address is not announced, but it will deal with the impact of science on society-a subject at once arresting and topical. The spirit of the age is less and less in sympathy with the view that science may be pursued regardless of its repercussions on the community; nor, in these times, may we be quite so complacent concerning the benefits conferred by science on society as was the fashion in the days of Samuel Smiles. Eugenic and dysgenic effects must be considered, and those who look to Sir Josiah Stamp for an analysis of these repercussions which shall be critical, far-reaching and provocative, are not likely to be disappointed.

The sectional presidential addresses cover a wide field, and in many instances deal directly with the bearing of scientific investigation on the 
life of the community. The list of the addresses is as follows :

Section A (Mathematical and Physical Sciences) : Prof. Allan Ferguson, "Trends in Modern Physics"*; Section B (Chemistry) : Prof. J. C. Philip, "The Training of the Chemist for the Service of the Community"*; Section C (Geology): Prof H. L. Hawkins, "Palæontology and Humanity"; Section D (Zoology) : Dr. Julian Huxley, "Natural Selection and Evolutionary Progress"; Section E (Geography): Brigadier H. S. L. Winterbotham, "Mapping of the Colonial Empire"*; Section F (Economic Science and Statistics) : Dr. C. R. Fay, "Some Aspects of Commercial Agriculture"; Section G (Engineering): Prof. W. Cramp, "The Engineer and the Nation"*; Section H (Anthropology): Miss D. A. E. Garrod, "The Upper Palæolithic in the Light of Recent Discovery"; Section I (Physiology): Prof. R. J. S. McDowall, "Integration of the Circulation"; Section J (Psychology) : Mr. A. W. Wolters, "Patterns of Experience"; Section K (Botany) : Mr. J. Ramsbottom, "The Uses of Fungi"*; Section L (Education): Sir R. Livingstone, "The Future in Education"; Section M (Agriculture): Prof. J. Hendrick, "Soil Science in the Twentieth Century"*.

The Council of the Association has evidently been studying its statutes, and has wisely interpreted the phrase, "to obtain more general attention for the objects of Science and the removal of any disadvantages of a public kind which impede its progress", as one of encouragement to the Council in its response to the growing public demand for a discussion of the more immediate bearing of advances in science on the life and wellbeing of the community. With the exception of the mathematical theorem which its discoverer announced as- "Thank Heaven, of no possible use to anyone, at any time, or in any circumstances", there are no advances in science which may not, potentially, influence the life of the community; but some- discoveries are more remote in their influence than others. Moreover, titles are misleading; and the new policy of indicating by an asterisk those subjects of more immediate public interest is one which should commend itself alike to the members of the Association and to the Press.

The programmes of the sections, even in their present brief form, illustrate in a very interesting fashion the tendency to move from isolated papers to discussions. Discussions, either within a section, or jointly between two sections, are likely to bulk largely in the Blackpool programme; and of these discussions quite a large fraction is concerned with topics of community interest. Thus, discussions on high voltages and on textiles, on chemistry and the community, on scientific problems of the poultry industry, on Abyssinia, on economic problems affecting Lancashire, on engineering problems of mass-amusement, on climate and health, on botany and gardening, on the social and cultural value of science, on the strain of modern civilisation, and on national nutrition and British agriculture, are examples, taken from the sectional programmes, of topics which have been starred as of immediate communal interest. And there is no lack of variety in the unstarred subjects for discussion. Genetics and the race concept, education for rural life, motor-car headlights, sea defences, the teaching of economics in schools, the agricultural geography of the Fylde, earth movements in north-east England, and the physical basis of living matter-these are but a selection from topics of general and of local interest.

The discussion, staged by Section $\mathrm{A}$, on the evolution of the solar system, brings back memories of that wider discussion on the evolution of the universe which was such a prominent feature of the London meeting of 1931. It is specially appropriate that this related, if rather more modest, topic should come to the front at the Blackpool meeting. For Sir Oliver Lodge, the doyen of the Association, whose memories of its meetings reach back to those remote days when John Tyndall's Belfast address raised such a storm, has, after two years' absence, announced his attention to attend the Blackpool meeting. It was at the London discussion that Sir Oliver made his latest formal contribution to the proceedings of Section A. Is it too much to hope that the Section will again have the privilege of hearing its old friend and whilom president on one of the many topics which have engaged his interest?

The evening discourses will be delivered by Capt. F. Kingdon-Ward, who will speak on planthunting and exploration in Tibet, and by $\mathrm{Mr}$. C. C. Paterson, who will deal with a subject of special interest to Blackpool-science and electric lighting.

A couple of generations ago, the Association was wont to arrange at its meetings popular addresses which were known as "Lectures to the Operative Classes". We have left such titles far behind today, but the practice survives, and public lectures of a popular type will be given during the week of the meeting in many of the neighbouring towns.

A number of most interesting sectional and general excursions have been arranged which should afford to members ample opportunity for making acquaintance with the beauty-spots and antiquities of Lancashire. The Lakes are well known, and an outstanding feature of the week will be a whole-day excursion to the Lakes on Saturday, September 12. A shorter Saturday 
excursion may be arranged which will give an opportunity to explore the Ribble valley and to see something of the work which has recently been carried out at Whalley Abbey. Sectional excursions and visits will include the Metropolitan. Vickers Works at Manchester, Stonyhurst and Rossall, the freshwater biological station at Wray Castle, and the laboratories of Imperial Chemical Industries Ltd. at Blackley.
A four-days' excursion in the Furness district is being arranged in collaboration with the Yorkshire Geological Society immediately preceding the meeting, and a four-days' excursion to the Isle of Man after the meeting is under consideration.

The Mayor and Mayoress of Blackpool (Alderman Walter Newman, J.P., and Miss Newman) will hold a reception in the Winter Gardens on Thursday evening, September 10.

\section{Scenic Geography at the Royal Academy}

"W HAT will this year's Academy teach us about the scenery of the world?" was the question uppermost in my mind as I entered Burlington House. It was with particular satisfaction that I noted several instructive studies of the scenery of cities. The sky-line of the eity is bolder than any which Nature can produce, but in the strong light of day the scene is generally confusing in its multiplicity of form, and in colour often drab and dull. But Mr. C. R. W. Nevinson's two studies of London in twilight illustrate the advantages of civic scenery without its drawbacks. "Hail and Fairwell" (730) gives us a last view of the round arches of Waterloo Bridge with the harmonious curves of the dome of St. Paul's in the background, with the grey of twilight changed to a deep and tender shade of blue by the amber glow of the street lighting. In his second study, "Battersea Twilight" (727), the sky-line beyond a foreground of the Embankment and river is dominated not by a Cathedral but an industrial building, the Battersea Power House with its two great chimneys. There is a story that Whistler replied to a friend who complained of the prominence of factory chimneys, "Call them campaniles". It is to be hoped that in a future exhibition Mr. Nevinson's study may be followed by one taken from a nearer stand-point where the details of Sir Giles Gilbert Scott's design can be seen, particularly the fluting of the chimneys which so greatly enhances the columnar effect. This is the artistic touch that campaniles share but which the older factory chimneys lack. It is a hopeful sign of the times that the architect of Liverpool Cathedral has been entrusted with the design of this great industrial building. If the practice becomes general of obtaining the best architectural advice for factory building, the social benefit will be great, for if these huge erections were made beautiful the community would realise better the romance of industrial achievement.

Among the studies of purely natural scenery none has more poetic appeal than Mr. Julius Olsson's large painting of "Land's End and Long. ships Light" (151). Below the dark cliff a broad band of foaming surf is lit by the moon, which shines through a rift in the sombre clouds. Two studies of the Cornish coast (246 and 541), by Mr. Charles Simpson, remind us of the importance of taking steps to preserve this wild shore as $\mathbf{8}$ sanctuary of scenery. Mr. Borlase Smart's "Along our North-West Coast" (540) is one of the few studies of the shore viewed from the sea, which when the land is mountainous is one of the most attractive aspects of natural scenery. The recent extension of the programme of pleasure cruises, now much better organised than heretofore, would provido the sea painter with a travelling studio for such studies. Thus, passing west of Teneriffe on the outward and to the east on the homeward voyage of the Almanzora, I recently saw the whole circumference of the wonderful Peak from an advantageous distance with exquisite effects of clond and sky.

Of mountain scenery there is a fine example in Mr. Harry Van der Weyden's "From the Path to Castellar" (121), in which the nobility of height in associated with the solemnity of shadowed valleye where the sun's declining rays can no longer penetrate.

The quiet charm of the fields, woods and rural architecture of the English countryside is the welcome theme of many works. Mr. Oliver Hall's "Leckhampton Court from the Lawn" (22) pos. sesses in full measure the restful dignity charac. teristic of this artist's work. Mr. Alfred J. Munnings's "A Farm in Suffolk" (60) illustrates the advantageous setting which the small undulations of the Suffolk landscape provide for the picturesque old farm houses. The suave lines of the rolling chalk downs are the subject of pleasant watercolours by the Very Rev. W. Foxley Norris, "Chanctonbury Ring" (777) and by Mr. Charles H. Larkin, "The Downs, Poynings, Sussex" (956). 